\title{
Impact of the new mental health services on rates of suicide and hospitalisations by attempted suicide, psychiatric problems, and alcohol problems in Brazil
}

\begin{abstract}
A sizeable proportion of all suicides have mental health issues in the background. The association between access to mental health care in the community and decreased suicide rates is inconsistent in the literature. Brazil undertook a major psychiatric reform strengthening psychiatric community-based care.
\end{abstract}

OBJECTIVE: To evaluate the impact of the new Brazilian community mental health care units (CAPS-Psychosocial-Community-Centres) on municipal rates of suicide, and hospitalisations by attempted suicide, psychiatric and alcohol problems.

METHOD: We performed robust multivariable negative binomial regression models with fixed effect for panel data from all 5,507 Brazilian municipalities. Suicide and hospitalization rates were calculated by sex and standardised by age for each municipality and year from 2008 to 2012. The main variable of interest was municipal CAPS coverage. RESULTS: CAPS municipal coverage was associated with lower suicide rates but this was not statistically significant (RR: 0.981; 95\% CI 0.952-1.011). However, increased CAPS coverage was associated with lower hospitalizations for attempted suicide (RR: 0.887; 95\% CI 0.841-0.935), psychiatric (RR: 0.841; 95\% CI 0.821-0.862), and alcohol problems (RR: 0.882 ; 95\% CI 0.860-0.904).

CONCLUSION: Our results suggest that access to community mental health services seems to reduce hospitalisations due to attempted suicide, psychiatric and alcohol problems but not suicidal rates. Therefore, increased investments in community mental health services in low-middle-income countries might decrease costs associated with potentially avoidable hospitalizations. 
Keywords: suicide; mental health services; hospitalisations 


\section{Introduction}

The proportion of people with mental health disorders receiving adequate treatment is low worldwide, especially in low-middle-income countries (LMIC) (Wang et al., 2007; Becker \& Kleinman, 2013). This treatment gap might contribute to the large number of overall disability-adjusted life years lost, andincreases the strain on social and general health services as well as the economic impact due to sickness absences and lower productivity (Scheffler \& WHO, 2011).

Even in high-income countries it is estimated that between $35 \%-50 \%$ of people with severe mental disorders receive no treatment for their conditions; in low-and-middleincome countries (LMIC) this percentage is estimated to be as high as $76 \%-85 \%$ (World Health Organization [WHO], 2015a). The number of mental health workers per 100,000 inhabitantsalso varies between low and high-income countries. Globally, it is estimated that there are 9 mental health workers per 100,000, with wide variations, from below $1 / 100,000$ inhabitants in low-income countries to over 50/100,000 inhabitants in highincome countries (WHO, 2015b). The budgets for mental health care in LMIC tend to be low: with an average yearly expenditure of less than US\$2 per capita and a large proportion of these funds going to inpatient care, especially large psychiatric hospitals (WHO, 2015b). All of the above reasons contribute to maintain this large gap in access to treatment for mental disorders in LMIC.

The low availability of mental health care services worldwide has prompted the World Health Organization to state as a priority aim "providing comprehensive, integrated and responsive mental health and social care services in community-based settings" as its second major objective in the Mental Health Action Plan 2013-2030. By the year 2020the aim is to increase service coverage for severe mental disorders by $20 \%$ (WHO, 2015a). 
The prevalence of mental disorders in Brazil varies from 20 to $56 \%$ (Santos \& Siqueira, 2010) depending on methodologies used and among the main factors associated are: gender, age, economic adversity, working conditions, and lifestyle (Santos \& Siqueira, 2010).While Brazil, an upper middle-income country (World Bank Data, 2017), has a high prevalence of mental health disorders, the gap in access to mental health care among those with mental disorders is large (Andrade et al., 2012). It is estimated that only $13 \%$ of people with a mental problem in Brazil gets treatment (Brasil, 2007).

Financial, structural and cultural barriers limit access to mental health care in Brazil. Low budgets, lack of trained primary care workers, stigma, and the lack of awareness of mental illnesses are amongst the main problems in Brazil (Santos \& Siqueira, 2010).

In 1978 Brazil reformulated its mental health policy, giving prominence to strengthening community-based approaches (Brasil, 2005). With the introduction of the new Brazilian Mental Health Policy anetwork of community mental health care units (CAPS - Centro de Atenção Psicosocial) (Brasil, 2013) was created with a progressive reduction in the number of existing psychiatric (Brasil, 2011a) and general hospital beds (Paim \& Almeida Filho, 2014). Integrating subsequently, the Mobile Emergency Service (SAMU), to assist with emergencies including those related to mental health problems (Brasil, 2011a).

The first CAPS was opened in 1987; the number of CAPS has steadily increased to reach 2,678 in 2015 (Datasus, 2017). CAPS are the main health care resource for people with severe and persistent mental disorders (Brasil, 2004). Patients can be referred from other health facilities, be brought in by their families or present themselves (Brasil, 2004). Three types of care are offered: Intensive; Semi-Intensive and Non-Intensive. All three service modalities can be delivered at home if necessary (Brasil, 2004). Among the 
services delivered by CAPS are: individual and group care; family sessions; community activities and assemblies (activities that gather professionals, users, family members or other guests, to discuss and evaluate referrals to the service) (Brasil, 2004).

There are different types of CAPS. CAPS I are the smallest units, covering 50,000 inhabitants per municipality. It is a service for adults with severe and persistent mental disorders, including disorders resulting from use of alcohol or other drugs. CAPS II is a mid-sized service, covering 100,000 inhabitants per municipality. CAPS III covering 150,000 or more inhabitants can deal with emergencies offering a 24-hour service every day. The CAPSi is specialized in the care of children and adolescents with mental disorders and CAPSad in the care of people who make harmful use of alcohol and other drugs, both are references to a territory of 150/200,000 inhabitants (Brasil, 2011b).

The emergency mobile services (SAMU) also contribute to mental health care in Brazil. They provide care to psychiatric emergencies, such as: psychoses, suicide attempts, depression, and organic brain syndromes (Brasil, 2003). SAMU was created in 2003, to offer 24-hour mobile emergency assistance with skilled team's staff, doctors, nurses, nursing assistants and rescue drivers (Brasil, 2003). SAMU is a component of the increased provision of mental health care, with the ability to provide support during crisis and coordinate mental health care assistance during emergencies (Brasil, 2003).

Since 1993, WHO has stated that the treatment of psychiatric disorders is an important step to prevent suicide (WHO, 1994).Among others, ambulatory mental health care has been shown to prevent suicidal behaviour (Tondo, Albert \& Baldessarini, 2006; Williams et al., 2008; Pirkola, Sund, Sailas \& Wahlbeck, 2009) reduce psychiatric hospitalizations (Tondo et al., 2006), and alcohol-related problems (Whitlock, Polen, Green, Orleans \& Klein, 2004). A sizeable proportion of all suicides are related to mental health issues (Bertolote, Fleischmann, De Leo \& Wasserman, 2004).Up to $90 \%$ of people who commit 
suicide have some psychiatric disorder; therefore, adequate access to diagnosis and treatment for the underlying disorder might help preventing suicides (Bertolote et al., 2004).

Suicide happens more often in those with depression, anxiety, substance abuse and personality disorders (Wasserman et al., 2012). In Denmark, the suicide risk among people with psychosis decreased with improvements in quality of inpatient and outpatient services (Nordentoft, Madsen \& Fedyszyn, 2015). A study done in Finland showed that well-developed community mental health services were associated with lower suicide rates compared with those orientated towards inpatient provision (Williams et al., 2008). A study in the US also found that health care access might prevent suicide. This study concluded that clinical intervention is a crucial element to prevent suicide (Tondo et al., 2006). Other studies showed contrasting results: in Austria, lower suicide rates were associated exclusively with psychotherapists' density, also suggesting that socioeconomic factors were stronger predictors of suicide than mental health care availability in thatcountry (Kapusta et al., 2009). A study in Norway found no association between changes in the delivery of mental health care, from impatient care to communitybased care, with suicide rates (Johannessen, Dieserud, Claussen, \& Zahl, 2011). All these studies used different measures to evaluate the association between mental health services and suicide rates and were done in different socioeconomic and cultural contexts. The paucity of studies across the world and contrasting results confirms the need of further studies to study this association in different contexts. As mental disorders increase the risk of suicide (Harris \& Barraclough, 1997; Mortensen, Agerbo, Erikson \& Westergaard-Nielsen, 2000; Nordentoft et al., 2015), improved treatment of mental illness could decrease suicide rates. However, the relationship between accessibility to mental health care and decreased suicide rates is inconsistent in the literature; some 
studies show a protective effect (Tondo et al. , 2006; Williams et al., 2008; Kapusta et al., 2009; Campo, 2009; While et al., 2012) whereas others have found no statically significant associations (Johannessen et al., 2011; Ross, Yakovlev \& Carson, 2012). The differences in coverage, quality and type of care provided in diverse countries may explain thesedifferences. In Brazil, there is no evidence to support an association in either direction.

The prevalence of mental illness and access to mental health care are not the only factors related to suicide. For instance, suicide seems to be associated with socioeconomic disadvantage (Williams et al., 2008). To understand the causation of suicide at a population level it is necessary to consider a range of factors including gender (rate of suicide of men to women worldwide varies from 3:1 to 7.5:1) (Nock et al., 2008), age (Hawton \& Van, 2009) and socioeconomic factors (Stack, 2000; Ying \& Chang, 2009; Kõlves, Milner \& Värnik, 2013) .Suicide seems to result from a complex interaction of biological, psychological, socio-cultural and economic factors (Brasil, 2013).

\section{Justification}

While implementation of new strategies of care is necessary, their evaluation is equally important, especially in Low Middle Income Countries (LMIC) where the mental health care gap is very high and resources limited. The experience of one LMIC can help other countries with similar levels of development since they often face similar challenges in mental health and suicide prevention. Although the Brazilian government invested heavily on mental health services, the impact on health outcomes is still unknown. Evaluating its impact is interesting for an innovative mental health system such as in Brazil where socioeconomic changes have taken place in a short period of time (Neri \& Souza, 2012). 
The objective of this study was to assess whether CAPS municipal coverage had an impact on a limited but important number of mental health indicators: suicide rates, hospitalizations by attempted suicide, and psychiatric and alcohol problems. In addition, we aimed to evaluate if the presence of emergency mobile care (SAMU) in the municipalities was associated with a decrease in suicide rates and also evaluate the influence of other factors (number of residents per household; \% households with one resident; percentage of Pentecostal Christians; \% employed people; availability of guns; urbanization rate; per capita income Brazilian Real (BR\$). Our hypotheses were that an increased availability of ambulatory mental health centres (CAPS) would reduce suicide rates and rates of hospitalizations by attempted suicide, other psychiatric problems and alcohol abuse.

\section{METHODS}

We used a mixed ecological design with a panel data of 5,507 Brazilian municipalities over five years, from 2008-2012. The panel dataset was balanced (no data missing) for any variable.

\section{Data Sources}

All data came from came from the Health Informatics Department of the Brazilian Ministry of Health (MS, 2016) including mortality data for each municipality, CAPS coverage, SAMU presence, hospitalizations by attempted suicide, and psychiatric and alcohol problems.

Demographic and socioeconomic variables (the mean number of residents per household, the percentage of households with only one resident, the percentage of people who reported affiliation to the Pentecostal church, the percentage of employed people, urbanization rates and per capita income) were obtained from the National Census Data 
for the years 2000 and 2010 from the Brazilian Institute of Geography and Statistics (IBGE). Variables for years 2008-2009 were calculated by linear interpolation and those for the years 2011 and 2012 by linear extrapolation. The linear trend was consistent with nationwide socioeconomic sample surveys that are conducted every year and collected by state-level organizations (Instituto Brasileiro de Geografia e Estatística [IBGE], 2017).

\section{Definition of the Variables}

Suicide was defined as death resulting from intentional self-harm according to the International Classification of Diseases, 10th revision (WHO, 2010a) codes X60 to X84. In Brazil mortality statistics use this classification. The outcome variable, suicide rate was calculated at the municipality level and standardized by age (for every five years) with a direct method. Rates were calculated for individuals $>=10$ years old, as it is a very rare event before this age (47 deaths under 10 in Brazil, from 2004-2012) (Scheffler \& WHO, 2011). The analysis investigated rates of suicide per 100,000 inhabitants, overall and stratified by sex for each municipality and year of analysis. All death certificates in Brazil are completed following the "International Medical Certificate of Cause of Death Model ", recommended by the World Health Assembly since 1948 (Brasil, 2001). Deaths due to external causes (suicide, homicide and accidents) are forwarded to the Medical Legal Institute (IML) (artigo $2^{\circ}$ da Resolução CFM n $\left.{ }^{\circ} .1 .779 / 2005\right)$ where the death certificates are emitted and signed by an examining doctor (Brasil, 2001). Diagnoses are based on the autopsy, on the analyses of the history covering the circumstances in which the death occurred, personal history of the victim, and suicide risk factors (Jorge, Gotlieb \&Laurenti, 2002).

\section{Rates of hospitalizations by attempted suicide, and psychiatric, and alcohol}

problemswere calculated as the number of hospitalizations by each of these reasons (we only accessed to the main reason for the hospitalizations) divided by the municipal 
population and presented as a rate per 100,000 inhabitants.

Coverage rate of Psychosocial Care Centre (CAPS), measures the coverage of the current Brazilian mental health program in each municipality per 100,000 inhabitants, based on the type of CAPS. The formula used for this indicator was: [(No. CAPS I x $0.5)+($ No. CAPS II $)+($ No. CAPS III x 1.5) + (No. CAPSi $)+($ No. CAPSad $)] /$ Populationx 100,000 (Brasil, 2009). CAPS coverage was included in the model in three formats: as continuous variable, as continuous with a limit of $100 \%$ coverage and stratifying by level of coverage (insufficient $<=0.20$; low $0.20-0.34$; average $0.35-0.49$; good 0.50- 0.69 and very good $>=0.70$ )

Mobile Emergency Service (SAMU) was classified as present or absent in each municipality independent of the number of units or size of the city. Assuming that when SAMU is implemented in a municipality, the number of units is enough to guarantee approximately $100 \%$ coverage of all emergency needs.

Variables included in the model as potential confounders for each municipality were: mean number of residents per household; percentage of households with only one resident; percentage of individuals who declared being Pentecostal; employment rate measuring the percentage of the population aged 16 years or over with a job; availability of guns using a proxy estimated as the percentage of suicides committed using guns (Kleck, 2004); urbanization rate or the percentage of individuals living in urban areas for that municipality; the monthly per capita income BR\$; availability of psychiatric hospital beds estimated as the number of psychiatric hospital beds available divided by the municipal population $\mathrm{x} 100,000$ and estimated similarly: availability of general hospital beds. These variables were selected because they were available in routine data and there was evidencein the literature (Bertolote, Fleischmann, De Leo \& Wasserman, 2004; Ying \& Chang, 2009; Kõlves et al., 2013; (Neri \& Souza, 2012) they might be 
associated with suicide and/or mental health related hospitalizations.

\section{Statistical Analysis}

A multivariate regression analysis was performed using a negative binomial (NB) regression for panel data with fixed-effects (FE) specification for each outcome of interest. The regression models were used because the outcome variables are count data and the Poisson model assumption that the mean is equal to the variance does not hold true, typically because the data are over-dispersed (Hilbe, 2011).

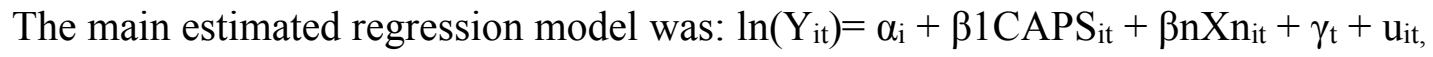
where $Y_{i t}$ was the suicide rate for the municipality i in year $t, \alpha_{i}$ was the fixed effect for the municipality $i$ and captured all unobserved time-invariant factors, $\mathrm{CAPS}_{\text {it }}$ was the CAPS coverage for the municipality $i$ in the year $t, \mathrm{Xn}_{i t}$ was the value of each $\mathrm{n}$ covariate of the model, including all demographic and socioeconomic determinants, in the municipality $i$ in the year $t, \gamma_{t}$ was the time-specific effect, and $u_{i t}$ was the error.

We specified a FE based on the Hausman test assuming that the time-invariant term could control for unobserved characteristics of the municipality (geographical, historical, socio-cultural, or socioeconomic characteristics) that did not change during the study period and could be correlated with the independent variables of the models. Four regression models were performed, for each of the 4 outcomes: suicide rates, rates of hospitalizations by attempted suicide, and psychiatric and alcohol problems. In model 1, the main independent variable was the CAPS municipality coverage, and the variables controlled for were: municipal mean number of residents per household; percentage of residences with only one resident; percentage of subjects who were PentecostalChristians; percentage of employed people; availability of guns, urbanization rate, municipal per capita income, availability of psychiatric hospital beds and availability of general hospital beds. We run the model overall and separately by gender. In model 2 , hospitalizations by 
attempted suicide was the main independent variable, controlling for the same variables used in the previous model. In model 3, hospitalizations by psychiatric problems were controlled by the variable municipal per capita income, availability of psychiatric hospital beds and availability of general hospital beds. Finally, in model 4 hospitalizations by alcohol problems was controlled by the variables: municipal mean number of residents per household; percentage of households with only one resident; percentage of Pentecostals; percentage of employed people; availability of psychiatric hospital beds and availability of general hospital beds.

A time variable (time-specific effect) used as continuous variable was introduced into the models to control for the national-level changes in suicide rates resulting from policy changes or secular trends that could affect all of the municipalities (Wooldridge, 2015).This time variable varied from 1 to 5 to represent the years 2008 to 2012 .

Sensitivity tests were performed to analyse the robustness of the results. Models with different specifications were fitted from the same dataset, including Poisson regressions with robust SEs and NB and Poisson models with continuous variables. The Akaike's Information Criterion (AIC) and the Bayesian Information Criterion (BIC) were used to establish which model best fitted the data (Hilbe, 2011). In our case the FE NB regression models were considered the most appropriate for the analysis. All statistical analyses were conducted using Stata (v.13).

This study was approved by the London school of Hygiene \& Tropical Medicine Ethics Committee, reference number: 11581.

\section{RESULTS}

Table 1 shows that suicide rate seems to have increased in Brazil from 2008 to 2012. This increase was more marked among women (12.1\%) but suicide remains three 
times more frequent among men. The municipal rate of hospitalizations by attempted suicide and psychiatric causes both decreased by almost $4 \%$ over this period. Hospitalization rate by alcohol problems remained almost unchanged over this period. The CAPS coverage and SAMU presence increased by 55\% and 57\%, respectively.

\section{------- INSERT TABLE 1}

The mean number of residents per household decreased while the percentage of people living alone increased. The percentage of Pentecostals, the per capita income, the percentage of employed people, and the urbanization rate also increased. While the availability of guns, availability of psychiatric and hospital beds decreased (see Table 1).

\section{------- INSERT TABLES $2 \& 3$}

The mean suicide rate (average annual rates per 100,000) in cities with no CAPS was higher than in municipalities with CAPS during the 5 years analysed, 7.9 and 6.7 respectively. However, CAPS coverage was associated only with hospitalizations but not suicide rates. Although there was a small negative association between CAPS coverage and suicide rates this was not statistically significant (RR: $0.981 ; 95 \%$ CI: $0.952-1.011$ ) (Table 2). Similar results were found stratifying this variable by diverse levels of coverage. As for hospitalizations, the CAPS coverage was significantly associated with a lower hospitalization rate due to attempted suicide (RR: $0.887 ; 95 \%$ CI: $0.841-0.935$ ), psychiatric (RR: 0.841; 95\% CI: 0.821-0.862) and alcohol problems (RR: 0.906; 95\% CI: 0.884-0.928) (Table 3).

Among the others determinants assessed, the percentage of people living alone was positively associated with suicide rates (RR: 1.063; 95\% CI: 1.011-1.118) and attempted suicide hospitalization rate (RR: 1.069; 95\% CI: 1.030-1.109). Availability of guns was positively associated with suicide rates (RR: 1.007; 95\% CI: 1.006-1.007) but not with attempted suicide hospitalization rates. Mean number of residents per household and percentage of Pentecostals were both negatively associated with suicide rate and rates 
of hospitalization by attempted suicide and alcohol problems. Urbanization was negatively associated with suicide rate and hospitalizations by attempted suicide while per capita income was associated with suicide rate and hospitalizations by psychiatric problems. Availability of psychiatric and general beds were not associated with suicide or hospitalizations by attempted suicide (Table $2 \boldsymbol{\&} \mathbf{3}$ ).

------ INSERT TABLE 4

When evaluating these variables by gender, among men the mean number of residents per household, percentage of Pentecostals and urbanization remain negatively associated while guns availability was positively associated with suicide rates. Among women, the percentage of people living alone remains positively associated while percentage of Pentecostals negatively associated with suicide rates (Table 2). Presence of SAMU was negatively associated with suicide rates (RR: $0.942 ; 95 \%$ CI: $0.888-0.999$ )

(Table 4).

\section{DISCUSSION}

We found that the level of municipal coverage of the new Mental Healthcare Centres (CAPS) had no significant impact on municipal suicide rates over the period studied. However, CAPS municipal coverage was clearly associated with lower rates of hospitalizations by attempted suicide, psychiatric and alcohol problems, even after controlling by availability of general and psychiatric beds. A $100 \%$ increase in the CAPS municipal coverage was associated with an $11 \%$ decrease in hospitalizations by attempted suicide, $16 \%$ by psychiatric and $12 \%$ by alcohol problems.

These findings might suggest that the provision of CAPS could help avoiding unnecessary hospitalizations for the reasons mentioned above. It might be possible to speculate that increased CAPS coverage reduces hospitalizations because more psychiatric problems are managed in community centres avoiding hospitalizations. This 
was one of the main objectives when the Brazilian reform was introduced. Nonetheless, it is important to emphasize that this study used an ecological design so we cannot reach firm conclusions on these possible explanations.

The current increased CAPS coverage does not seem to be associated with a decrease in suicide rates in Brazil, as found in similar studies done in Austria (Kapusta et al., 2009) and Norway (Johannessen et al., 2011). Even with the coverage improvement (increase of almost $56 \%$, from 0.26 in 2008 to 0.40 in 2012) it still falls short of the national goalset by the Brazilian Ministry of Health, of achieving 0.77 coverage (Brasil, 2013). It may need more services than are currently offered to have a significant impact on suicide rates. Furthermore, the trend of coverage expansion also is not equitable; the spatial distribution of CAPS still reflects the structural inequalities among regions (Andrade et al., 2012). Services are unequally distributed across the country (Brasil, 2007).

Another concern would be the quality of services provided by CAPS. An adequate coverage of CAPS is certainly needed, but coverage alone cannot be effective if CAPS cannot offer adequate services: the objective is to have physical and human resources with trained specialized professionals to assist patients at risk to be able to effectively impact on the mental health population, preventing hospitalizations by attempted suicide and suicide. Studies using surveys could give a better understanding of the problems related with quality of the services offered by CAPS. For instance, although there is a suicide prevention manual for mental health teams, with an emphasis on CAPS (Brasil, 2006), no specific training seems to be in place for professionals working in CAPS to deal with the population at risk of suicide yet (WHO, 2010b). The type of treatment on offer might also be important. While in Brazil the traditional use of the psychoanalysis approach remains very common, studies on current treatments have 
demonstrated the Cognitive Behavioural Therapy (CBT) approach might be more effective to treat mental health problems and especially to prevent suicide (Tarrier, Taylor, \& Gooding, 2008; Daigle, Pouliot, Chagnon, Greenfield \& Mishara, 2011; Robinson, Hetrick \& Martin, 2011; Alavi, Sharifi, Ghanizadeh \& Dehbozorgi, 2013).

Referrals from other services to CAPS can also be a challenge. The links of CAPS with other health services would allow expeditious access to the population most at risk. A review of the literature showed that only $29.5 \%$ of people who had suicide ideation, plans, and/or attempts in the last year used a mental health service (Hom, Stanley \& Joiner, 2015). In Brazil community health agents are responsible for home visits, we think they could be very important, if well-prepared, to identify people at potential risk, especially those who do not seek help.

As in any other developing country, the number of professionals available can be another limitation at CAPS. Hiring more professionals but also maximising community sources to delivery mental health care could be an alternative. Training nonspecialist people to deliver psychological treatments and multicomponent stepped care has shown effectiveness (Patel \& Thornicroft, 2009). It could be especially interesting in Brazil where the limitless population size is in stark contrast to the limited resources available.

A limited type of treatment on offer is another issue that may explains the lack of impact of CAPS on suicide rates. CAPS services focus on the most severe cases of mental disorders (Brasil, 2004). However, considering that suicide is a multi-causal phenomenon and not exclusively related to psychiatric problems (Hawton \& Van, 2009) it is particularly important to provide care also to less severe cases. Since CAPS is the central service for mental health issues in Brazil it should also be able to efficiently assist any 
case in high psychological distress and in risk of suicide. Otherwise, specific services for suicide prevention should be implemented in the country.

Summarising, coverage, quality, lack of training for suicide prevention, and a lack of referrals from other services all might potentially impact on the capacity of CAPS to deliver an effective service to prevent suicide. Coupled with a lack of professionals and limited types of treatment on offer we see as some of possible reasons why increased CAPS coverage has still had no effect at the aggregate level on suicide rates in Brazil.

The emergency assistance, SAMU was also evaluated in the current study. Our results indicate a positive association at municipal level, in that municipalities with SAMU had lower suicide rates. A timely and effective response in emergency situations could be a powerful action to prevent suicide. Those people who received SAMU assistance had higher chances of being referred to mental health services. The WHO advises that ensuring that communities should receive appropriate interventions when facing crisis and that individuals in a crisis situation should always have access to emergency mental health care (WHO, 2014). Targeting emergency health providers as potential gatekeepers to prevent suicide might be important.

In addition to mental health care it is necessary to consider the influences of other factors also associated with suicide. In the present study the percentage of people living alone was positively associated with suicide rates and hospitalizations by attempted suicide. The percentage of people living alone is increasing in Brazil, while the mean number of residents per household is decreasing. These changes are related with Brazilian economic growth and the decrease in fertility rates (Victora et al., 2011), living alone and social isolation might increase mortality (Holt-Lunstad, Smith, Baker, Harris \& Stephenson, 2015), including that through suicide. The percentage of Pentecostals and mean number of residents per household, were both negatively associated with suicide 
rates, hospitalizations by attempted suicide and by alcohol problems. Therefore, since all these three variables related with socialization were associated with suicide, we can conclude that promoting socialization can be an important tool to prevent suicide in the Brazilian municipalities.

The percentage of employed people was not significantly associated with suicide rates. In Brazil the number of informal workers is high and, therefore, this variable might notreflect the real proportion of people working. Urbanization was negatively associated with suicide rates and attempted suicide related hospitalizations. Highly urban areas in Brazil have also higher per capita income and lesser income inequality, both factors associated with suicide rates (Machado, Rasella \& Santos, 2015). In addition, urban areas also offer more opportunities to access healthcare in general and especially mental healthcare services.

As in other countries, suicide rates in Brazil also vary by gender. It is increasing faster among women (12.1\%) but it remains over three times higher among men. Evaluating the association of the previous factors with suicide rates by gender showed that most of the associations remained among men but not among women. The limited number of suicides among women may have influenced this finding. The percentage of people living alone remained positively associated with female suicide rates, while mean number of residents per household, percentage of Pentecostals and urbanization remained negatively associated and availability of guns positively associated with male suicide rates. In Brazil men have higher involvement with violence and therefore have more access to arms (Reichenheim et al., 2011). Higher access to guns has been shown as a risk factor for suicide (Anglemyer, Horvath \& Rutherford, 2014). 
Considering the effect of all these factors on suicide rates, an effective prevention program to reduce suicide rates would need to be broader. Especially as deprivation situations can also lead to limited access in mental health care.

In addition to mental health assistance, it would be necessary to invest also in other sectors such as social care, education and welfare protection. A good mental health program needs to be used in conjunction with other multi sectoral actions. A good mental health program is unlikely to be enough to prevent suicide.

\section{Limitations and Strengths of the Study}

The main limitation of this study is that it is a contextual not an individual level study and therefore no conclusions can be extended to individuals. This is also a strength, in that it investigates impact at an aggregate level of service coverage. An ecological design was the only possible approach due to data availability and it increased external validity of the results, only the use of aggregate data allows the study of all Brazilian population longitudinally.

Another limitation could be that large municipalities and small municipalities have equal weight in the analysis. However, since the objective of our study was the impact evaluation: any municipality and its service implementation should have the same importance and the same weight. This is particularly important in the Brazilian context, where $90 \%$ of the municipalities - in particular in the rural and poorest areas - have less than 50,000 inhabitants. A weight associated with the municipality population would have given great influence to very large municipalities such as Sao Paulo or Rio de Janeiro and their CAPS and SAMU services. Also, the use of large numbers of small areas in ecological studies reduces the possibility of ecological fallacy (Haynes, Lovett, Reading, Langford \& Gale, 1999; Wakefield, 2008). 
A further limitation is the inclusion of SAMU as present or absent in the municipality regardless of its size. It would be more rigorous to use the number of SAMU units per population; but the information is only available in this format. However, we assume that, when SAMU has been implemented, the number of units will be proportional to the size of the population and its estimated emergency needs.

The CAPS coverage variable also has some limitations, as it does not take into account demand, access or even quality of services offered.

Finally, the completeness and quality of the data is a potential limitation. However, by 2003-05 it was estimated that mortality data is of good quality in at least $80 \%$ of Brazil (Szwarcwald, 2008) and our data is from 2008-12. The data on socioeconomic determinants from the national census and CAPS coverage and hospitalizations from Ministry of Health, all have been assessed as having high standards (Datasus, 2017; IBGE, 2017).

One of the main strengths of the current study is the use of panel data analysis rather than traditional cross-sectional data analysis. Longitudinal data allows evaluating the influence of social contextual features over time and provide stronger evidence for causal inference. The use of a nationwide analysis of all municipalities assures the generalizability of the results to all of Brazil. The evaluation of the Brazilian Mental Health Care may be a useful case study for other countries starting to reform psychiatric care or even to those which already have it but never evaluated it. We suggest that panel data analysis can be a powerful tool to evaluate the impact of policies and interventions in health at a lower cost, especially in countries where funding for extensive evaluations is limited.

\section{Conclusion}


In Brazil, suicide rates have increased in the last decade, the increased municipal coverage of the new community mental healthcare centres (CAPS) was not significantly associated with variation in suicide rates. However, CAPS does not focus on suicide prevention at present.

Nevertheless, this increased coverage in community mental healthcare seems to be associated with a decrease in hospitalizations by attempted suicide, psychiatric and alcohol problems, even after adjusting for the relative reduction in general and psychiatric hospital beds. A reduction in unnecessary hospitalizations is in keeping with the aims of introducing CAPS.

Additional studies using data individual level data would help to elucidate further the impact of these new services in the health of the Brazilian population. Evaluating the effectiveness of mental health services is as important as increasing its coverage, in order to ensure that mental health care in the communities avoid unnecessary hospitalizations and the costs involved, especially in LMIC where the resources are limited overall. 


\section{References}

1. Alavi, A., Sharifi, B., Ghanizadeh, A., \&Dehbozorgi, G. (2013). Effectiveness of cognitive-behavioral therapy in decreasing suicidal ideation and hopelessness of the adolescents with previous suicidal attempts. Iranian journal of pediatrics, 23(4), 467.

2. Andrade, L. H., Wang, Y. P., Andreoni, S., Silveira, C. M., Alexandrino-Silva, C., Siu, E. R., ...\&Viana, M. C. (2012). Mental disorders in megacities: findings from the Sao Paulo megacity mental health survey, Brazil. PloS one, 7(2), e31879

3. Anglemyer, A., Horvath, T., \& Rutherford, G. (2014). The Accessibility of Firearms and Risk for Suicide and Homicide Victimization Among Household MembersA Systematic Review and Meta-analysis. Annals of internal medicine, 160(2), 101-110.

4. Becker, A. E., \&Kleinman, A. (2013). Mental health and the global agenda. New England Journal of Medicine, 369(1), 66-73.

5. Bertolote, J. M., Fleischmann, A., De Leo, D., \& Wasserman, D. (2004). Psychiatric diagnoses and suicide: revisiting the evidence. Crisis, 25(4), 147-155.

6. Brasil. Ministério da Saúde. (2001). Manual de instruções para o preenchimento da declaração de óbito : 3. ed. . Brasília : Ministério da Saúde : Fundação Nacional de Saúde. Mortalidade. 2. Sistema de Informações. I. Brasil. Ministério da Saúde. II. Brasil. FundaçãoNacional de Saúde.

7. Brasil. Ministério da Saúde (2003). Política nacional de atenção às urgências. Brasília: Ministério da Saúde 228 p.: il. - (Série E. Legislação de Saúde) 1. Serviços Médicos de Emergência. 2. Legislação Sanitária. I. Brasil. Ministério da Saúde. II. Título. III. Série.

8. Brasil. Departamento de Ações Programáticas Estratégicas. (2004). Saúde mental no SUS: oscentros de atençãopsicossocial. Ministério da Saúde.

9. Brasil. Ministério da Saúde. (2005). Reforma psiquiátrica e política de saúde mental no Brasil. Brasília: Ministério da Saúde.

10. Brasil. Ministério da Saúde. (2006). Prevenção do Suicídio: manual dirigido a profissionais das equipes de saúde mental.

11. Brasil. Ministério da Saúde.(2007). Saúde Mental em Dados. Secretaria de Atenção à Saúde. Departamento de Ações Programáticas e Estratégicas. Coordenação Geral de Saúde Mental: Ministério da Saúde. 
12. Brasil. Ministério da Saúde. (2009). Portaria n ${ }^{0}$ 2.669, de 3 de novembro de 2009. Estabelece as prioridades, objetivos, metas e indicadores de monitoramento e avaliação do Pacto pela Saúde, noscomponentes pela Vida e de Gestão, e as orientações, prazos e diretrizes do seuprocesso de pactuação para o biênio 20102011. Ministério da Saúde.

13. Brasil. Ministério da Saúde. (2011a). Portaria $n^{0} 3.088$, de 23 de dezembro de 2011. Institui a Rede de AtençãoPsicossocial para pessoas com sofrimentooutranstorno mental e com necessidadesdecorrentes do uso de crack, álcool e outrasdrogas, no âmbito do Sistema Único de Saúde. DiárioOficial da RepúblicaFederativa do Brasil, (247).

14. Brasil. Ministério da Saúde. (2011b). Saúde Mental em Dados - 8, ano VI, no 8. Informativo eletrônico. Brasília. Recovered in August 2016 from: www.saude.gov.br

15. Brasil. Ministério da Saúde. (2013). Secretaria de Gestão Estratégica e Participativa. Departamento de ArticulaçãoInterfederativa. Caderno de diretrizes, objetivos, metas e indicadores: 2013-2015.

16. Campo, J. V. (2009). Youth suicide prevention: does access to care matter?. Current opinion in pediatrics, 21(5), 628-634.

17. Daigle, M. S., Pouliot, L., Chagnon, F., Greenfield, B., \&Mishara, B. (2011). Suicide attempts: prevention of repetition. The Canadian Journal of Psychiatry, 56(10), 621-629.

18. Datasus.(n.d). Recovered in September 2016 from: http://www2.datasus.gov.br/DATASUS/index.php?area=0204\&id=6906\&VObj $=$ http://tabnet.datasus.gov.br/cgi/deftohtm.exe?cnes/cnv/estab

19. Harris, E. C., \& Barraclough, B. (1997). Suicide as an outcome for mental disorders. A meta-analysis. The British Journal of Psychiatry, 170(3), 205-228.

20. Hawton, K. \& Van, H. K. (2009). Suicide. The Lancet, Vol.373(9672), pp.13721381 [Peer Reviewed Journal]

21. Haynes, R., Lovett, A., Reading, R., Langford, I. H., \& Gale, S. (1999). Use of homogeneous social areas for ecological analyses: A study of accident rates in pre school children. The European Journal of Public Health, 9(3), 218-222.

22. Hilbe, J. M. (2011). Negative binomial regression. Cambridge University Press.

23. Holt-Lunstad, J., Smith, T. B., Baker, M., Harris, T., \& Stephenson, D. (2015). Loneliness and social isolation as risk factors for mortality: a meta-analytic 
review. Perspectives on Psychological Science, 10(2), 227-237.

24. Hom, M. A., Stanley, I. H., \& Joiner, T. E. (2015). Evaluating factors and interventions that influence help-seeking and mental health service utilization among suicidal individuals: a review of the literature. Clinical psychology review, 40, 28-39.

25. Instituto Brasileiro de Geografia e Estatística (IBGE). (n.d.). Recovered in September 2016 from: http://www.ibge.gov.br/home

26. Johannessen, H. A., Dieserud, G., Claussen, B., \&Zahl, P. H. (2011). Changes in mental health services and suicide mortality in Norway: an ecological study. $B M C$ health services research, 11(1), 68.

27. Jorge, M. H. P. D. M., Gotlieb, S. L. D., \&Laurenti, R. (2002). O sistema de informaçõessobremortalidade: problemas e propostas para o seuenfrentamento IIMortesporcausasexternas. RevistaBrasileira de Epidemiologia, 5(2), 212-223.

28. Kapusta, N. D., Niederkrotenthaler, T., Etzersdorfer, E., Voracek, M., Dervic, K., Jandl-Jager, E., \&Sonneck, G. (2009). Influence of psychotherapist density and antidepressant sales on suicide rates. ActaPsychiatricaScandinavica, 119(3), 236242.

29. Kleck, G. (2004). Measures of gun ownership levels for macro-level crime and violence research. Journal of Research in Crime and Delinquency, 41(1), 3-36.

30. Kõlves, K., Milner, A., \&Värnik, P. (2013). Suicide rates and socioeconomic factors in Eastern European countries after the collapse of the Soviet Union: trends between 1990 and 2008. Sociology of health \& illness, 35(6), 956-970.

31. Machado, D. B., Rasella, D., \& Dos Santos, D. N. (2015). Impact of income inequality and other social determinants on suicide rate in Brazil. PloS one, 10(4), $\mathrm{e} 0124934$.

32. Mortensen, P. B., Agerbo, E., Erikson, T., Qin, P., \&Westergaard-Nielsen, N. (2000). Psychiatric illness and risk factors for suicide in Denmark. The Lancet, 355(9197), 9-12.

33. Neri, M. C., \& Souza, P. H. C. F. D. (2012). A décadainclusiva (2001-2011): desigualdade, pobreza e políticas de renda.

34. Nock, M. K., Borges, G., Bromet, E. J., Cha, C. B., Kessler, R. C., \& Lee, S. (2008). Suicide and suicidal behavior. Epidemiologic reviews, 30(1), 133-154.

35. Nordentoft, M, Madsen, T \& Fedyszyn, I. (2015) Suicidal behaviour and mortality in first-episode psychosis.JNervMent Dis. May;203(5):387-92. doi: 
10.1097/NMD.0000000000000296.

36. Paim, J. S., \& Almeida Filho, N. D. (2014). Saúdecoletiva: teoria e prática. In Saúdecoletiva: teoria e prática. MedBook.

37. Patel, V., \& Thornicroft, G. (2009). Packages of care for mental, neurological, and substance use disorders in low-and middle-income countries: PLoS Medicine Series. PLoS medicine, 6(10), e1000160.

38. Pirkola, S., Sund, R., Sailas, E., \&Wahlbeck, K. (2009). Community mentalhealth services and suicide rate in Finland: a nationwide small-area analysis. The Lancet, 373(9658), 147-153.

39. Reichenheim, M. E., De Souza, E. R., Moraes, C. L., de Mello Jorge, M. H. P., Da Silva, C. M. F. P., \& de Souza Minayo, M. C. (2011). Violence and injuries in Brazil: the effect, progress made, and challenges ahead. The Lancet, 377(9781), 1962-1975.

40. Robinson, J., Hetrick, S. E., \& Martin, C. (2011). Preventing suicide in young people: systematic review. Australian and New Zealand journal of psychiatry, 45(1), 3-26.

41. Ross, J. M., Yakovlev, P. A., \& Carson, F. (2012). Does state spending on mental health lower suicide rates?. The Journal of Socio-Economics, 41(4), 408-417.

42. Santos, É. G. D., \&Siqueira, M. M. D. (2010). Prevalência dos transtornosmentaisnapopulaçãoadultabrasileira: umarevisãosistemática de 1997 a 2009. J. bras. psiquiatr, 59(3), 238-246.

43. Scheffler, R. M., \& World Health Organization. (2011). Human resources for mental health: workforce shortages in low-and middle-income countries.

44. Stack, S. (2000). Suicide: a 15-year review of the sociological literature part I: cultural and economic factors. Suicide and Life-Threatening Behavior, 30(2), 145-162.

45. Szwarcwald, C. L. (2008). Strategies for improving the monitoring of vital events in Brazil. International journal of epidemiology, 37(4), 738-744.

46. Tarrier, N., Taylor, K., \& Gooding, P. (2008). Cognitive-behavioral interventions to reduce suicide behavior: a systematic review and meta-analysis. Behavior modification, 32(1), 77-108.

47. Tondo, L., Albert, M. J., \&Baldessarini, R. J. (2006). Suicide rates in relation to health care access in the United States: an ecological study. The Journal of clinical psychiatry, 67(4), 517-523. 
48. Victora, C. G., Aquino, E. M., do Carmo Leal, M., Monteiro, C. A., Barros, F. C., \&Szwarcwald, C. L. (2011). Maternal and child health in Brazil: progress and challenges. The Lancet, 377(9780), 1863-1876.

49. Wakefield, J. (2008). Ecologic studies revisited. Annu. Rev. Public Health, 29, 75-90.

50. Wang, P. S., Aguilar-Gaxiola, S., Alonso, J., Angermeyer, M. C., Borges, G., Bromet, E. J., ...\&Haro, J. M. (2007). Use of mental health services for anxiety, mood, and substance disorders in 17 countries in the WHO world mental health surveys. The Lancet, 370(9590), 841-850.

51. Wasserman, D., Rihmer, Z., Rujescu, D., Sarchiapone, M., Sokolowski, M., Titelman, D., \& Carli, V. (2012). The European Psychiatric Association (EPA) guidance on suicide treatment and prevention. European psychiatry, 27(2), 129141.

52. While, D., Bickley, H., Roscoe, A., Windfuhr, K., Rahman, S., Shaw, J., \&Kapur, N. (2012). Implementation of mental health service recommendations in England and Wales and suicide rates, 1997-2006: a cross-sectional and before-and-after observational study. The Lancet, 379(9820), 1005-1012.

53. Whitlock, E. P., Polen, M. R., Green, C. A., Orleans, T., \& Klein, J. (2004). Behavioralcounseling interventions in primary care to reduce risky/harmful alcohol use by adults: a summary of the evidence for the US Preventive Services Task Force. Annals of internal medicine, 140(7), 557-568.

54. Williams, M. E., Latta, J., \&Conversano, P. (2008). Eliminating the wait for mental health services. The journal of behavioral health services \& research, 35(1), 107-114.

55. Wooldridge, J. M. (2015). Introductory econometrics: A modern approach. Nelson Education.

56. World Bank Data. (n.d). World Bank country and lending groups. Recovered in October 2016 from: https://datahelpdesk.worldbank.org/knowledgebase/articles/906519-world-bankcountry-and-lending-groups

57. World Health Organization. (1994). Guidelines for the primary prevention of mental, neurological and psychosocial disorders. 5. Staff burnout.

58. World Health Organization. (2010a). International classification of diseases (ICD). http://apps. who. int/classifications/apps/icd/icd10online/. 
59. World Health Organization (WHO). (2010b). Prevenção do Suicídio: um recurso para conselheiros: Genebra: OMS.

60. World Health Organization (WHO). (2014). Preventing suicide: a global imperative. Recovered in 2016 from:http://apps.who.int/iris/bitstream/10665/131056/8/9789241564878_eng.pdf ?ua $=1 \&$ ua $=1$

61. World Health Organization. (2015a). Mental health action plan 2013-2020.; 2013. WHO web site http://scholar. google. com/scholar.

62. World Health Organization (2015b). Mental health atlas 2014. World Health Organization.

63. Ying, Y. H., \& Chang, K. (2009). A study of suicide and socioeconomic factors. Suicide and life-threatening behavior, 39(2), 214-226. 